\title{
Gait Training using Pneumatically Actuated Robot System
}

\author{
Natasa Koceska ${ }^{1}$, Saso Koceski ${ }^{1}$, Pierluigi Beomonte Zobel ${ }^{2}$ \\ and Francesco Durante ${ }^{2}$ \\ ${ }^{1}$ Faculty of Computer Science, University "Goce Delce" - Stip, Stip, \\ ${ }^{2}$ Applied Mechanics Laboratory, DIMEG, University of L'Aquila, L'Aquila \\ ${ }^{1}$ Macedonia \\ 2Italy
}

\section{Introduction}

Locomotor disability is the most commonly reported type of disability. It is defined as a person's inability to execute distinctive activities associated with moving both himself and objects, from place to place and such inability resulting from affliction of musculoskeletal and/or nervous system. In this category entered the people with paraplegia, quadriplegia, multiple sclerosis, muscular dystrophy, spinal cord injury, persons affected by stroke, with Parkinson disease etc.

The number of people with locomotor disabilities is growing permanently as a result of several factors, such as: population growth, ageing and medical advances that preserve and prolong life. Worldwide statistics about locomotor disability show that:

- $\quad$ in Australia: $6.8 \%$ of the Australian population had a disability related to diseases of the musculoskeletal system, which is $34 \%$ of the persons with any kind of disability;

- $\quad$ in USA: there are more than 700.000 Americans who suffer a stroke each year, making it the third most frequent cause of death and the leading cause of permanent disability in the country. 10.000 suffer from traumatic spinal cord injury, and over 250.000 are disabled by multiple sclerosis per year;

- $\quad$ in Italy: 1.200.000 people have declared the locomotor disabilities.

Rehabilitation is very important part of the therapy plan for patients with locomotor dysfunctions in the lower extremities. The goal of rehabilitation is to help the patient return to the highest level of function and independence possible, while improving the overall quality of life - physically, emotionally, and socially.

Locomotor training in particular, following neurological injury has been shown to have many therapeutic benefits. Intensive training and exercise may enhance motor recovery or even restore motor function in people suffering from neurological injuries, such as spinal cord injury (SCI) and stroke. Repetitive practice strengthens neural connections involved in a motor task through reinforcement learning, and therefore enables the patients a faster and better relearning of the locomotion (walking). Practice is most effective when it is task-specific. Thus, rehabilitation after neurological injury should emphasize repetitive, task-specific practice that promotes active neuromuscular recruitment in order to maximize motor recovery. 
Conventional manual therapy includes specific exercises for strengthening and practicing of one single movement at time. The more sophisticated therapy which over the years has established itself as an effective intervention for improving over-ground walking function, involves practice of stepping on a motorized treadmill with manual assistance and partial bodyweight support (BWS). This kind of therapy makes use of a suspension system to provide proper upright posture as well as balance and safety during treadmill walking. This is accomplished through a harness that removes a controllable portion of the weight from the legs, redistributing it to the trunk and groin, and in the same time allowing free movement of the patients' arms and legs. The movement is provided by a slow moving treadmill. The treadmill constant rate of movement provides rhythmic input which reinforces a coordinated reciprocal pattern of movement. Proper coordination is further assisted by the manual placement of the feet by the therapist. The BWS reduces the demands on muscles, which may enable the patient to work on improving the coordination of the movement while gradually increasing the strength of muscles (Miller et al., 2002). The controlled environment may also increase patient confidence by providing a safe way to practice walking (Miller et al., 2002). As patients progress, the BWS can be gradually decreased, challenging the patient to assert more postural control and balance (Miller et al., 2002).

This rehabilitation strategy was derived from research showing the effect of suspending spinalized cats in harnesses over treadmills (Visintin \& Barbeau, 1989) From this work with spinalized cats, it was determined that not only a reciprocal locomotor program can be generated at a spinal cord level by central pattern generators, but also, this pattern can be controlled through sensory input. By pulling the stance leg back with the pelvis stabilized in a harness, the treadmill causes extension to the hip of the weight bearing leg, which triggers alternation in the reciprocal pattern controlled by the central pattern generator (Grillner, 1979). Since it was demonstrated by (Barbeau \& Rossignol, 1987) that the quality of locomotion in spinalized cats improved if they were provided a locomotor training program, it seems reasonable to expect that humans with locomotor disabilities might benefit from this type of training.

Clinical studies have confirmed that individuals who receive BWS treadmill training following stroke (Hesse et al., 1994) and spinal cord injury (Wernig et al., 1999) demonstrate improved electromyographic (EMG) activity during locomotion (Visintin et al., 1998), walk more symmetrically (Hassid et al., 1997), are able to bear more weight on their legs.

However, manual assistance, during the BWS treadmill training, relies on physiotherapy procedures which are extremely labour intensive. It is carried out by 2 or 3 physiotherapists, sitting next to the treadmill, and manually guiding patient's legs in coordination with a treadmill. For therapists this training is exhaustive, therefore, training sessions tend to be short and may limit the full potential of the treatment. Manual assistance also lacks repeatability and precision. During the manual therapy it is very difficult for even the most proficient and skilled therapist to provide a proper gait pattern and in that way to maintain high-quality therapy across a full training session of patients, who require this type of attention. Also, manually assisted treadmill training lacks objective measures of patient performance and progress.

A promising solution for assisting patients during rehabilitation process is to design robotic devices. They may enhance traditional treatment techniques by enabling rehabilitation of all 
the joints together, which is more effective that training only one joint at time; they will provide more precise and repetitive gait trajectory, which was the main problem with the manual therapy; they could accurately measure and track the patient's impairments over the rehabilitation course; they could potentially augment recovery of ambulation in people following neurological injury by increasing the total duration of training and reducing the labor-intensive assistance provided by physical therapists. In the general setting of these robotic systems, a therapist is still responsible for the nonphysical interaction and observation of the patient by maintaining a supervisory role of the training, while the robot carries out the actual physical interaction with the patient.

\section{Robot devices for gait training - state of the art}

Several research groups are working on development of robot devices for "gait training". One example of automated electromechanical gait training device is 'Lokomat' (Colombo et al., 2000). It is a motor driven exoskeleton device that employs a body weight support suspension system and treadmill. Locomat has four rotary joints that drive hip and knee flexion/extension for each leg. The joints are driven in a gait-like pattern by precision ball screws connected to DC motors. The patient's legs, strapped into an adjustable aluminum frame, are moved with repeatable predefined hip- and knee-joint trajectories on the basis of a position-control strategy. Lokomat systems enables longer and individually adapted training sessions, offering better chances for rehabilitation, in less time and at lower cost compared to existing manual methods.

Another commercially available gait training device is Gait Trainer. It is a single degree-offreedom powered machine that drives the feet trough a gait-driven trajectory. Gait Trainer applies the principle of movable footplates, where each of the patients' feet is positioned on a separate footplate whose movements are controlled by a planetary gear system, simulating foot motion walking. Gait Trainer use a servo-controlled motor that sense the patients' effort, and keeps the rotation speed constant (Hesse et al., 2000). A potential limitation with the Gait Trainer is that the system does not directly control the knee or hip joints, so a manual assistance of one physiotherapist is needed to assist their proper movements. Gait Trainer might not be suitable for non-ambulatory people with weak muscles but only for those that have some degree of control of the knee/hip joints.

HapticWalker is programmable footplate machine, with permanent foot machine contact (Schmidt et al., 2005). The system comprises two 3 DOF robot modules, moving each foot in the sagittal plane. Foot movement along the two base axes in this plane (horizontal, vertical) is performed by linear direct drive motors, which move independently on a common rail, but are connected via a slider-crank system. A limitation of the HapticWalker is that the interaction only takes place at the foot sole so that typical poor joint stability of stroke patients cannot be controlled, for example to prevent hyperextension of the knee (similar to the GaitTrainer). Furthermore the cutaneous input at the foot sole with such a system is unnatural, which might disturb training effectivity.

LOPES (Lower Extremity Powered Exoskeleton) robot is a combination of an exoskeleton robot for the legs and an externally supporting end-effector robot for the pelvis (Veneman et al., 2005). The joints of the robot (hip, knee) are actuated with Bowden-cable driven series elastic actuators. Impedance control is used as a basic interaction control outline for the exoskeleton. 
PAM is a device that can assist the pelvic motion during stepping using BWST, and it's used in combination with POGO- the pneumatically operated gait orthosis (Aoyagi et al., 2007). Most of these devices are using electric motors as actuators. The use of electric motors, together with the specifically designed mechanism for converting their motion, is increasing the production costs of these devices.

This research is focused on design of pneumatically driven exoskeletal device for gait rehabilitation (developed in the Laboratory of Applied Mechanics at University of L'Aquila, Italy). The use of the pneumatic actuators is reasonable due to their large power output at a relatively low cost. They are also clean, easy to work with, and lightweight. Moreover, the choice of adopting the pneumatic actuators to actuate the prototype joints is biologically inspired. Indeed, the pneumatic pistons are more similar to the biological muscles with respect to the electric motors. They provide linear movements, and are actuated in both directions, so the articulation structures do not require the typical antagonistic scheme proper of the biological joints.

In summary, the pneumatic actuators represent the best tradeoff between biological inspiration, ease of employment and safe functioning due to the compliance of air, on one hand, and production costs, on the other.

\section{Mechanical design of the rehabilitation system}

Designing an exoskeleton device for functional training of lower limbs is a very challenging task. From an engineering perspective, the designs must be flexible to allow both upper and lower body motions, once a subject is in the exoskeleton, since walking involves synergy between upper and lower body motions. It must be also a light weight, easy wearable and must guarantee comfort and safety. From a neuro-motor perspective, an exoskeleton must be adjustable to anatomical parameters of a subject.

Considering these characteristics an exoskeleton structure with 10 rotational DOF was studied and realized. An optimal set of DOF was chosen after studying the literature on gait, and in order to allow the subject to walk normally and safely in the device.

The degrees of freedom are all rotational, two of them are on the pelvis level, two for the hips, two for the knees, and four for the ankles (Fig.1).

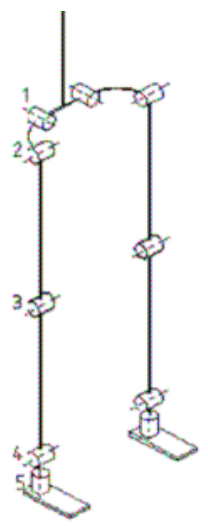

Fig. 1. DOF of the developed exoskeleton 
The robot moves in parallel to the skeleton of the patient, so that no additional DOF or motion ranges are needed to follow patient motions.

The mechanical structure of the shapes and the dimensions of the parts composing the exoskeleton are human inspired and have an ergonomic design.

The inferior limbs of the exoskeleton are made up of three links corresponding to the thighbone, the shinbone and the foot. The thighbone link is $463 \mathrm{~mm}$ long and has a mass of $0.5 \mathrm{~kg}$ and the shinbone link is $449 \mathrm{~mm}$ long and has a mass of $0.44 \mathrm{~kg}$. For better wearability of the exoskeleton an adjustable connection between the corset of polyethylene (worn by the patient) and the horizontal rod placed at the pelvis level is provided. Moving the exoskeleton structure up for only $25 \mathrm{~mm}$, the distance between the centre of the knee joint and the vertical axes of the hip articulation, is reduced to $148 \mathrm{~mm}$, while the corset remains in the same position. This way the system is adaptable to different patient dimensions.

In order to realize a prototype with anthropomorphic structure that will follow the natural shape of the human's lower limbs, the orientation and position of the human leg segments were analyzed. In the case of maximum inclination, the angle formed by the vertical axis and a leg rod is $2.6^{\circ}$, observed in frontal plane (Fig. 2).
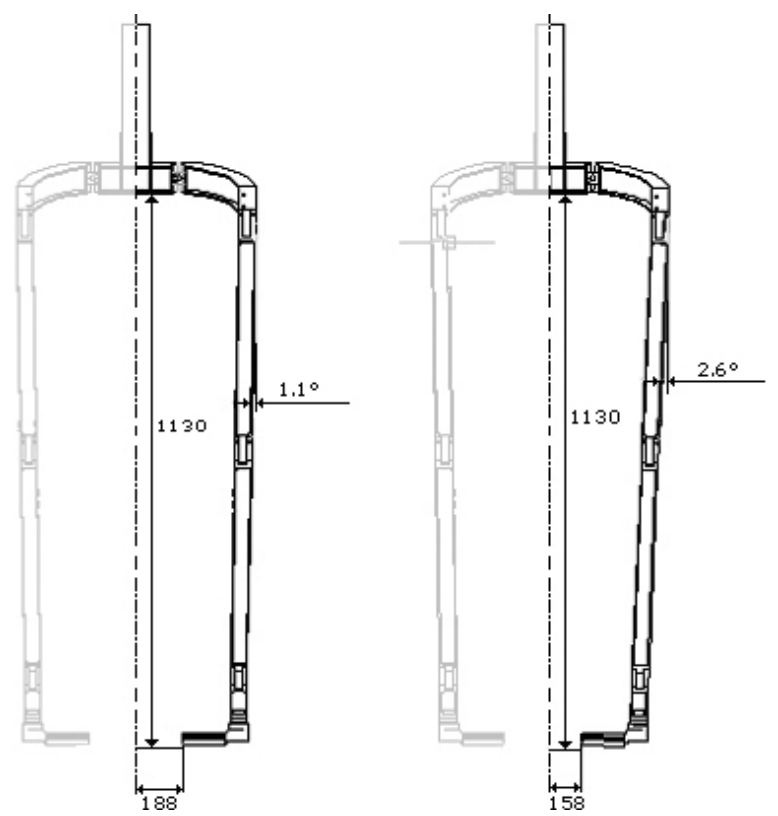

Fig. 2. Positioning of the exoskeleton shinbone and thighbone link, realized following the human leg position

The inclination of $1.1^{\circ}$ was chosen for the stand position, while other $1.5^{\circ}$ are given by a lateral displacement of $30 \mathrm{~mm}$, when the banking movement occurs. In this way the ankle joint is a little bit moved towards the interior side with respect to the hip joint, following the natural profile of the inferior limbs in which the femur is slightly oblique and form an angle of $9^{\circ}$ with the vertical while for the total leg this angle is reduced to $3^{\circ}$ (Fig. 3). 


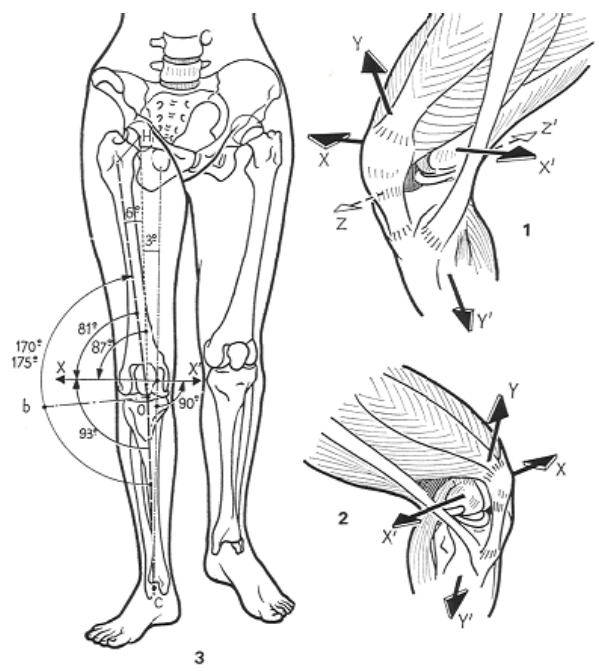

Fig. 3. Orientation and position of the human leg segments

The structure of the exoskeleton is realized in aluminum which ensures a light weight and a good resistance.

Rehabilitation system is actuated by 4 pneumatic actuators, two for each inferior limb of the exoskeleton (Fig. 4). The motion of each cylinder's piston (i.e. supply and discharge of both cylinder chambers) is controlled by two pressure proportional valves (SMC-ITV 1051312CS3-Q), connected to both cylinder chambers.

Hip and knee angles, of our rehabilitation system, are acquired by rotational potentiometers.
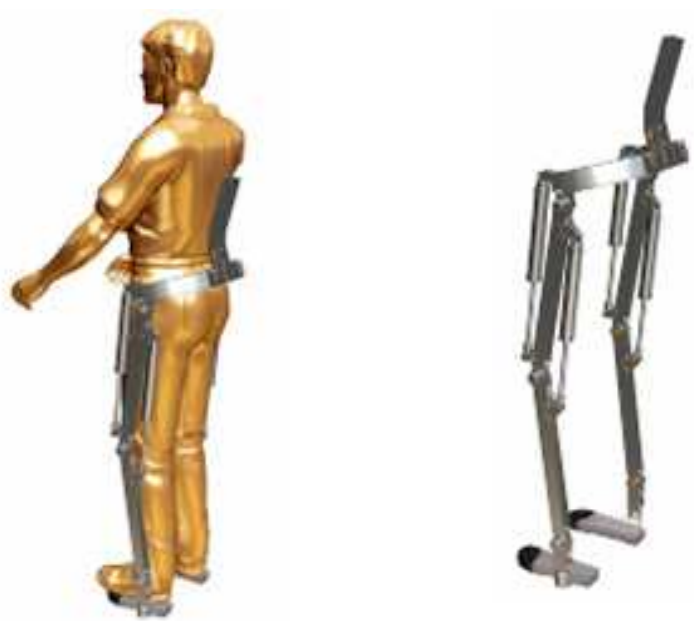

Fig. 4. Mechanical ergonomic structure of the exoskeleton with pneumatic actuators

In order to guarantee the safety of the patient, mechanical safety limits (physical stops), are placed on extreme ends of the allowed range of motion of each DOF. 
The overall exoskeleton structure is positioned on a treadmill and supported, at the pelvis level, with a space guide mechanism that allows vertical and horizontal movements. The space guide mechanism also prevents a backward movement caused by the moving treadmill belt. Space guide mechanism is connected with the chassis equipped with a weight balance system (Fig.5), which ensure balance during walking. The developed system is capable to support person heavy less than $85 \mathrm{~kg}$.

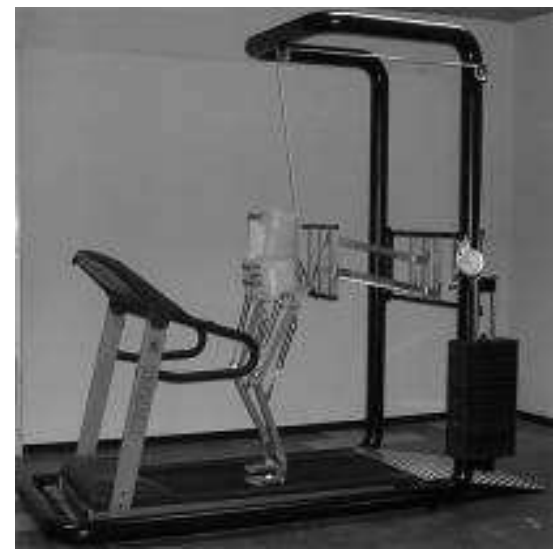

Fig. 5. Realized prototype of the overall rehabilitation system

\section{Kinematical behaviour and joint forces}

In order to develop the control system, it is useful to analyze the actuator forces necessary to move the mechanical system with reference to the shinbone and thighbone angular positions. Since the system is a rehabilitation one, with slow velocities, dynamic loads will be neglected in the following. The articulations have only one DOF or they are actuated by only one pneumatic actuator, Fig.4. The kinematic scheme of the leg is shown on the Fig.6a.
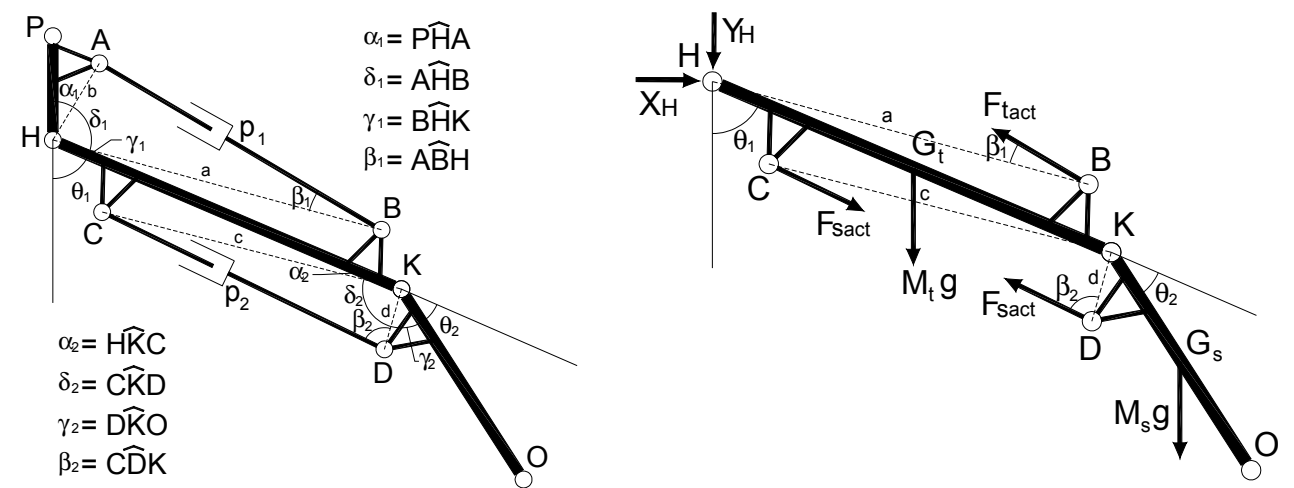

Fig. 6. a) Kinematic articulation scheme and b) free body diagram of the leg 
The $p_{1}$ segment represents the pneumatic actuator of the thighbone, the $p_{2}$ segment represents the pneumatic actuator of the shinbone whereas the hip angle position is indicated by the $\theta_{1}$ angle with reference to the vertical direction and the knee angle position is indicated by the $\theta_{2}$ angle with reference to the thighbone direction.

By means of simple geometric relations the process that calculates the length of the actuator of the shinbone once known the rotation angle $\theta_{2}$ is described with (1). The equations (1) show this process for the shinbone, considering the geometrical structure and the connections between different components.

$$
\left\{\begin{array}{l}
\delta_{2}=\pi-\theta_{2}-\gamma_{2}-\alpha_{2} \\
\mathrm{p}_{2}=\sqrt{c^{2}+d^{2}-2 c d \cos \delta_{2}}
\end{array}\right.
$$

After the calculation of the actuators length $p_{2}$, the angle $\beta_{2}$ can be easily deduced as in (2):

$$
\beta_{2}=\sin ^{-1}\left(\frac{c \sin \delta_{2}}{p_{2}}\right)
$$

$F_{\text {Sact }}$ represents the force supplied by the shinbone pneumatic actuator, whereas the arrow indicated by $M_{S g}$ shows the opponent force caused by the gravity as for the shinbone. $M_{S}$ is the approximate sum of the mass of the shinbone and the foot applied in the centre of mass of the shinbone.

From a simple torque balance with respect to the point $K$, Fig. $6 \mathrm{~b}$, the relation between $F_{\text {Sact }}$ and the angular positions $\theta_{1}$ and $\theta_{2}$ is derived as in (3).

$$
F_{\text {Sact }}=\frac{M_{S} g L_{K G s} \sin \left(\theta_{1}-\theta_{2}\right)}{d \sin \left(\beta_{2}\right)}
$$

From (1), (2) and (3) it can be seen that the force supplied by the shinbone pneumatic actuator can be expressed as a function of the $\theta_{1}$ and $\theta_{2}$ angle, obtained by the rotational potentiometers.

As the knee articulation also the hip articulation of the prototype has only one DOF and thus is actuated by only one pneumatic actuator as it can be seen on Fig.4. The hip articulation scheme is again shown on the Fig.6a as a part of the overall scheme of the leg. By simple geometric relations, the process that calculates the actuator length knowing the rotation angle $\theta_{1}$, is described with (4).

$$
\left\{\begin{array}{l}
\delta_{1}=\pi-\theta_{1}-\gamma_{1}-\alpha_{1} \\
\mathrm{p}_{1}=\sqrt{a^{2}+b^{2}-2 a b \cos \delta_{1}}
\end{array}\right.
$$

For a certain actuator length $p_{1}$, the angle $\beta_{1}$ can be easily deduced as in (5).

$$
\beta_{1}=\sin ^{-1}\left(\frac{b \sin \delta_{1}}{p_{1}}\right)
$$

$F_{\text {Tact }}$ indicates the force supplied by the thighbone pneumatic actuator, whereas the arrow indicated by $M_{T g}$ shows the opponent force caused by the gravity as for the thighbone. $M_{T}$ is 
the approximate sum of the weights of the thighbone applied in the centre of mass of the thighbone.

From a simple torque balance with respect to the point $H$, Fig. $5 b$, the $F_{\text {Tact }}$ value depending on the angular positions of hip and knee is derived. Equation (6) shows the relation found for the hip articulation.

$$
\mathrm{F}_{\text {Tact }}=\frac{M_{T} g L_{H G_{T}} \sin \theta_{1}+M_{S} g\left[L_{H K} \sin \theta_{1}+L_{K G_{S}} \sin \left(\theta_{1}-\theta_{2}\right)\right]}{a \sin \beta_{1}}
$$

From equations (4), (5) and (6) it can be seen that the force supplied by the thighbone pneumatic actuator also can be expressed as a function of the $\theta_{1}$ and $\theta_{2}$ angles obtained by the rotational potentiometers.

So, analytic relations between the forces provided by the pneumatic actuators and the torques needed to move the hip and knee articulations have been found. In particular, in our case it is useful to analyze the forces necessary to counteract the gravitational load acting on the thighbone and shinbone centre of mass, varying the joints angular position, because it offers the possibility of inserting a further compensation step in the control architecture in order to compensate the influence of errors, due to modelling and/or external disturbances, during the movements.

\section{Numerical solution of the inverse kinematic problem}

Walking is a complicated repetitious sequence of movement. The human walking gait cycle in its simplest form is comprised of stance and swing phases.

The stance phase which typically represents $60 \%$ of gait cycle is the period of support, while the swing phase for the same limb, which is the remaining $40 \%$ of the gait cycle, is the nonsupport phase [13]. Slight variations occur in the percentage of stance and swing related to gait velocity.

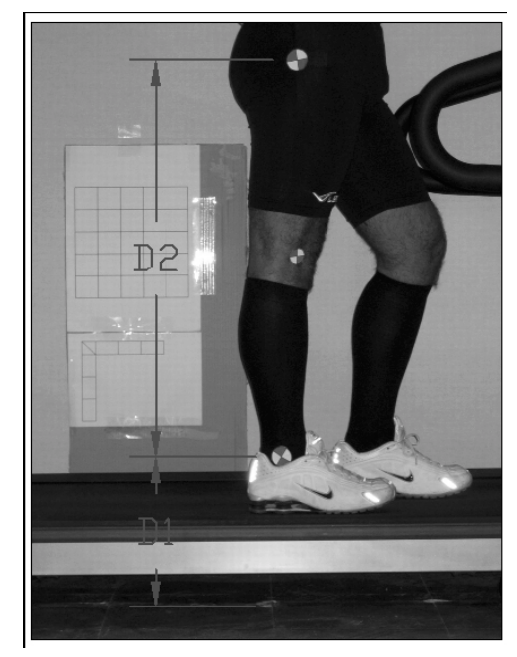

Fig. 7. Position of the markers 
To analyze the human walking, a camera based motion captured system was used in our laboratory. Motion capturing of a one healthy subject walking on the treadmill, was done with one video camera placed with optical axis perpendicular in respect of the sagittal plane of the gait motion. The subject had a marker mounted on a hip, knee and ankle.

An object with known dimensions (grid) was placed inside the filming zone, and it was used like reference to transform the measurement from pixel to distance measurement unit (Fig. 7). The video was taken with the resolution of 25 frame/s.

The recorded video was post-processed and kinematics movement parameters of limbs' characteristic points (hip, knee and ankle) were extracted. After that, the obtained trajectory was used to resolve the problem of inverse kinematics of our lower limb rehabilitation system. The inverse kinematic problem was resolved in numerical way, with the help of Working Model 2D software (Fig. 8). By the means of this software the target trajectory that should be performed by each of the actuators was determined.

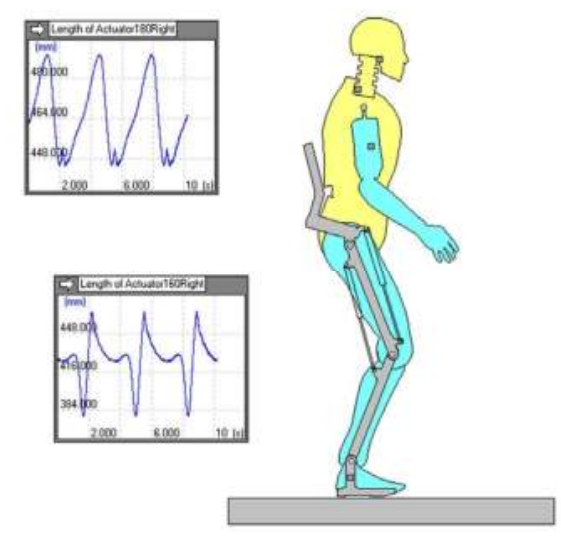

Fig. 8. Working Model 2D was used to obtain the actuators length, velocity and forces applied

\section{Control architecture}

The overall control architecture is presented with the diagram on the Fig. 9. In particular, it is based on fuzzy logic controllers which aim to regulate the lengths of thighbone and shinbone pneumatic actuators. The force compensators are calculating the forces necessary to counteract the gravitational load acting on the thighbone and shinbone center of mass, varying the joints angular position.

The state variables of the pneumatic fuzzy control system are: the actuator length error $E$, which is the input signal and two output control signals Urear and Ufront which are control voltages of the valves connected to the rear chamber and front chamber respectively.

Actuator length error in the system is given by:

$$
E(k T)=R(k T)-L(k T)
$$

where, $R(k T)$ is the target displacement, $L(k T)$ is the actual measured displacement, and $T$ is the sampling time.

Based on this error the output voltage, that controls the pressure in both chambers of the cylinders, is adjusted. Seven linguistic values non-uniformly distributed along their 
universe of discourse have been defined for input/output variables (negative large-NL, negative medium-NM, negative small-NS, zero-Z, positive small-PS, positive medium-PM, and positive large-PL). For this study trapezoidal and triangular-shaped fuzzy sets are chosen for input variable and singleton fuzzy sets for output variables.

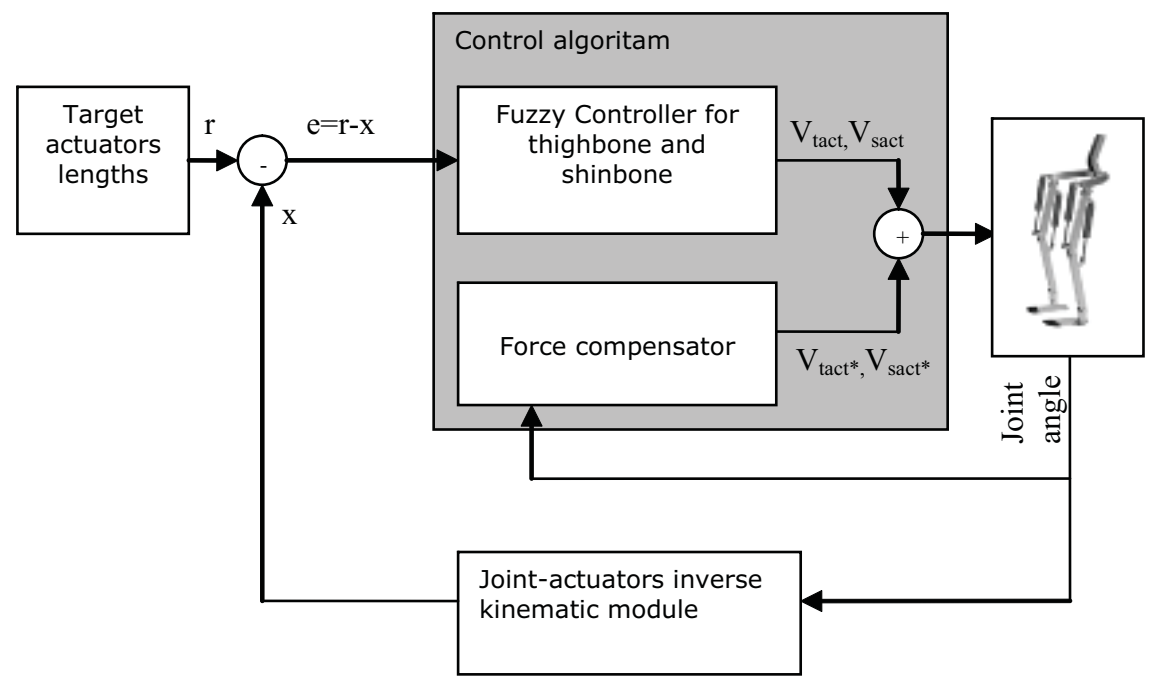

Fig. 9. Control architecture diagram

The membership functions were optimized starting from a first, perfectly symmetrical set. Optimization was performed experimentally by trial and test with different membership function sets. The membership functions that give optimum results are illustrated in Figs. 10,11 and 12 .

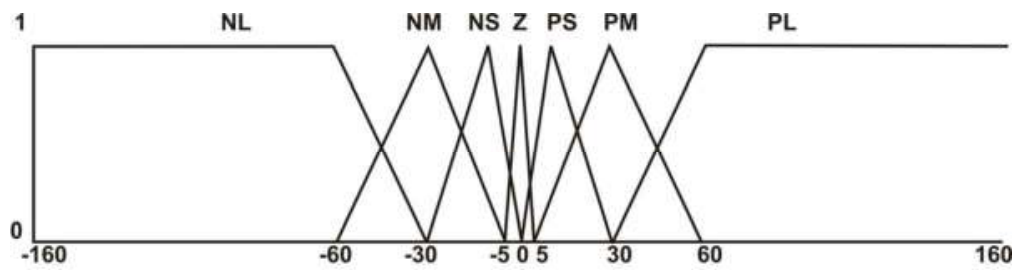

Fig. 10. Membership functions of input variable $\mathrm{E}$

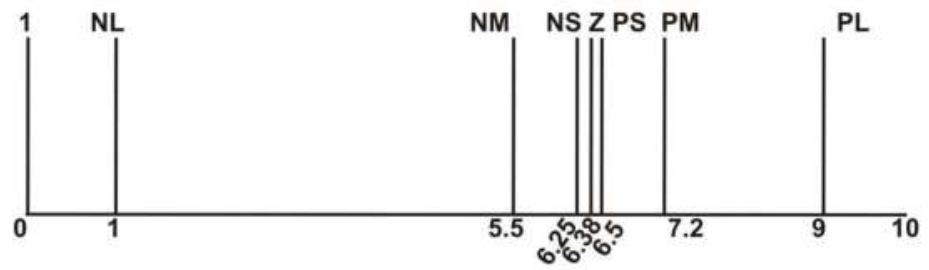

Fig. 11. Membership functions of output variable $\mathrm{U}_{\text {front }}$ 


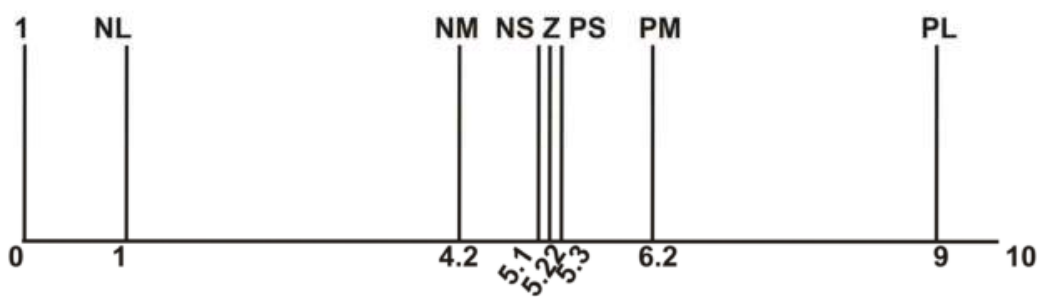

Fig. 12. Membership functions of output variable $U_{\text {rear }}$

The rules of the fuzzy algorithm are shown in Table 1 in a matrix format.

The max-min algorithm is applied and centre of gravity (CoG) method is used for deffuzzify and to obtain an accurate control signal. Since the working area of cylinders is overlapping, the same fuzzy controller is used for both of them. The force compensators are calculating the forces necessary to counteract the gravitational load acting on the thighbone and shinbone centre of mass, varying the joints angular position.

\begin{tabular}{|c|c|c|c|}
\hline Rule n $^{\circ}$ & E & ANT & POS \\
\hline 1 & PL & PL & NL \\
\hline 2 & PM & PM & NM \\
\hline 3 & PS & PS & NS \\
\hline 4 & Z & Z & Z \\
\hline 5 & NS & NS & PS \\
\hline 6 & NM & NM & PM \\
\hline 7 & NL & NL & PL \\
\hline
\end{tabular}

Table 1. Rule matrix of the fuzzy controller

Target pneumatic actuators lengths obtained by off-line procedure were placed in the input data module. In this way there is no necessity of real-time calculation of the inverse kinematics and the complexity of the overall control algorithm is very low. The feedback information is represented by the hip and knee joint working angles and the cylinder lengths.

The global control algorithm runs inside an embedded PC104, which represents the system supervisor. The PC104 is based on Athena board from Diamond Systems, with real time Windows CE.Net operating system, which uses the RAM based file system. The Athena board combines the low-power Pentium-III class VIA Eden processor (running at $400 \mathrm{MHz}$ ) with on-board $128 \mathrm{MB}$ RAM memory, 4 USB ports, 4 serial ports, and a 16-bit low-noise data acquisition circuit, into a new compact form factor measuring only $4.2^{\prime \prime} \times 4.5^{\prime \prime}$. The data acquisition circuit provides high-accuracy; stable 16-bit A/D performance with $100 \mathrm{KHz}$ sample rate, wide input voltage capability up to $+/-10 \mathrm{~V}$, and programmable input ranges. It includes 4 12-bit $\mathrm{D} / \mathrm{A}$ channels, 24 programmable digital I/O lines, and two 
programmable counter/timers. A/D operation is enhanced by on-board FIFO with interrupt-based transfers, internal/external A/D triggering, and on-board A/D sample rate clock.

The PC 104 is directly connected to each rotational potentiometer and valves placed onboard the robot.

In order to decrease the computational load and to increase the real-time performances of the control algorithm the whole fuzzy controller was substituted with a hash table with interpolated values and loaded in the operating memory of the PC104.

\section{Experimental results}

To test the effectiveness of the proposed control architecture on our lower limbs rehabilitation robot system, experimental tests without patients were performed, with a sampling frequency of $100 \mathrm{~Hz}$, and a pressure of $0.6 \mathrm{MPa}$.

The larger movements during the normal walking occur in the sagittal plane. Because of this, the hip and the knee rotational angles in sagittal plane were analyzed. During normal walking, the hip swings forward from its fully extended position, roughly $-20 \mathrm{deg}$, to the fully flexed position, roughly $+10 \mathrm{deg}$. The knee starts out somewhat flexed at toe-off, roughly $40 \mathrm{deg}$, continues to flex to about $+70 \mathrm{deg}$ and then straightens out close to $10 \mathrm{deg}$ at touch-down. Schematic representation of the anatomical joint angle convention is shown in Figure 13.

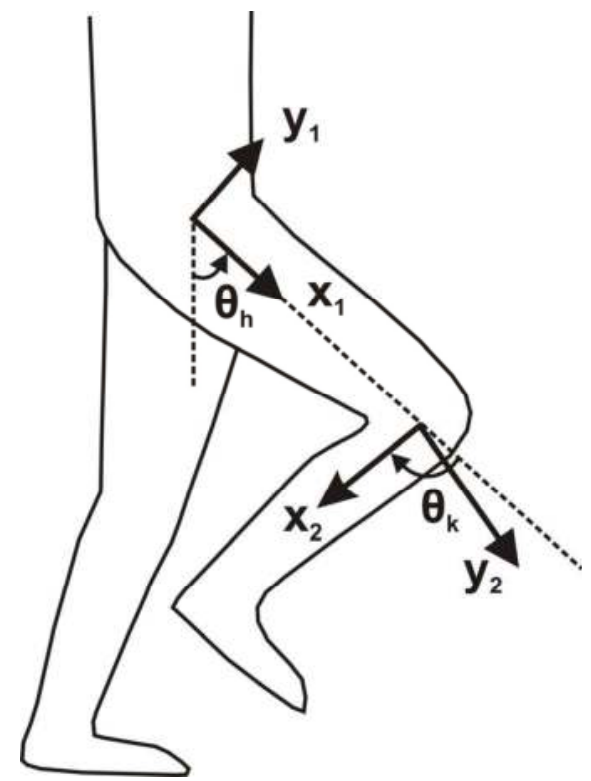

Fig. 13. Schematic representation of the anatomical joint angle convention

Figure 14 and Figure 15 show the sagittal hip and knee angle as function of time, of both human (position tracking measurement with leg-markers) and robot (joint angle measurements). 


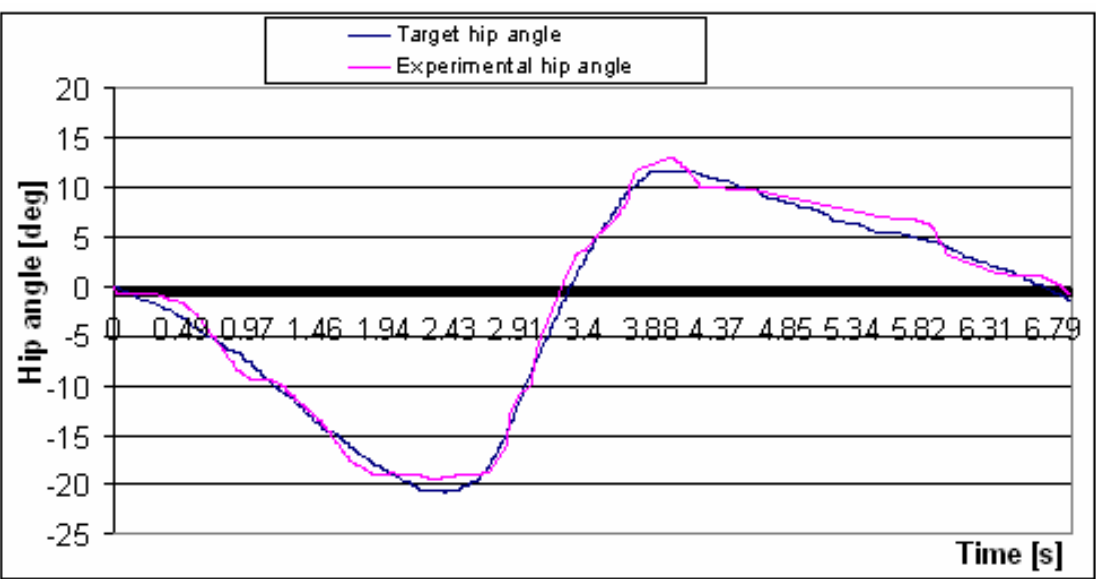

Fig. 14. Comparison of target and experimentally obtained hip angle as function of time

The results from the experiments show that the curves have reached the desired ones approximately. However, error (which is max. 5 degrees) exists, but doesn't affect much on final gait trajectory.

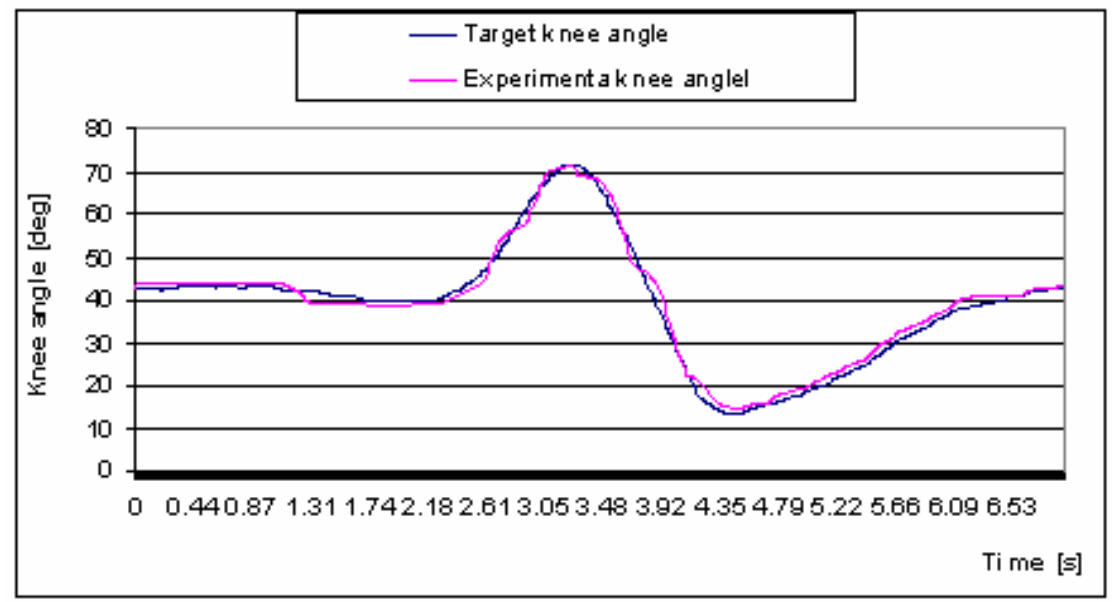

Fig. 15. Comparison of target and experimentally obtained knee angle as function of time

\section{Conclusion}

Powered exoskeleton device for gait rehabilitation has been designed and realized, together with proper control architecture. Its DOFs allow free leg motion, while the patient walks on a treadmill with its weight, completely or partially supported by the suspension system.

The use of pneumatic actuators for actuation of this rehabilitation system is reasonable, because they offer high force output, good backdrivability, and good position and force control, at a relatively low cost. 
The effectiveness of the developed rehabilitation system and proposed control architecture was experimentally tested. During the experiments, the movement was natural and smooth while the limb moves along the target trajectory.

In order to increase the performance of this rehabilitation system a force control loop should be implemented as a future development. The future work also foresees two more steps of evaluation of the system: experiments with voluntary healthy persons and experiments with disable patients.

\section{References}

Aoyagi, D.A., Ichinose, W. E. I., Harkema, S. J. H, Reinkensmeyer, D J. R, \& Bobrow, J. E. B. (Sep. 2007) A Robot and Control Algorithm That Can Synchronously Assist in Naturalistic Motion During Body-Weight-Supported Gait Training Following Neurologic Injury, IEEE Transactions on neural systems and rehabilitation engineering, vol.15, no. 3 .

Barbeau H, Rossignol S. Recovery of locomotion after chronic spinalization in the adult cat. Brain Res. 1987; 412(1):84-95.

Colombo G., Joerg M., Schreier R., Dietz V., Treadmill training of paraplegic patients using a robotic orthosis, J. Rehabil. Res. Dev. 17 (2000) 35-42.

Grillner S. Interaction between central and peripheral mechanisms in the control of locomotion. Prog Brain Res. 1979;50:227-235.

Hassid, E.H., Rose, D.R., Commisarow, J.C., Guttry, M.G. \& Dobkin, B.D. (1997), Improved gait symmetry in hemiparetic stroke patients induced during body weight supported treadmill stepping, J. Neurol. Rehabil. 11, 21-26.

Hesse, S.H., Bertelt, C.B., Schaffrin, A.S., Malezic, M. M., \& Mauritz, K.M. (October 1994), Restoration of gait in non-ambulatory hemiparetic patients by treadmill training with partial body weight support, Arch. Phys. Med. Rehabil. 75, 1087-1093.

Hesse, S.H. \& Uhlenbrock, D.U. (2000), A mechanized gait trainer for restoration of gait, J. Rehabil. Res. Development, vol. 37, no. 6, pp. 701-708.

Hornby, T.H., Zemon, D.Z. \& Campbell, D.C. (Jan. 2005), Robotic-assisted, bodyweightsupported treadmill training in individuals following motor incomplete spinal cord injuri, Physical Therapy, vol. 85, no. 1, 52-66.

Jezernik, S.J., Colombo, G.C., Keller, T.K., Frueh, H.F. \& Morari, M. M. (Apr. 2003), Robotic orthosis lokomat: A rehabilitation and research tool, Neuromodulation, vol. 6, no. 2, pp. 108-115.

Miller EW, Quinn ME, Seddon PG. Body weight support treadmill and overground ambulation training for two patients with chronic disability secondary to stroke. Phys Ther. 2002;82:53-61.

Schmidt H., Hesse S., Bernhardt R., Kruger J., Hapticwalker-A novel haptic foot device, ACM Trans. Appl. Perception (TAP), vol. 2, no. 2, pp. 166-180, Apr. 2005.

Veneman J, Kruidhof R, van der Helm FCT, van der Kooy H. Design of a Series Elastic- and Bowdencable-based actuation system for use as torque-actuator in exoskeleton-type training robots. Proceedings of the ICOOR 2005. 2005.

Visintin M, Barbeau H. The effects of body weight support on the locomotor pattern of spastic paretic patients. Can J Neurol Sci. 1989;16:315-325. 
Visintin, M.V., Barbeau, H.B, Bitensky, N.B, \& Mayo, N.M. (1998), Using a new approach to retrain gait in stroke patients through body weight support and treadmill training, Stroke 29,1122-1128.

Wernig, A.W., Nanassy, A.N. \& Muller, A.M. (1999), Laufband (treadmill) therapy in incomplete paraplegia and tetraplegia, J. Neurotrauma 16, 719-726. 


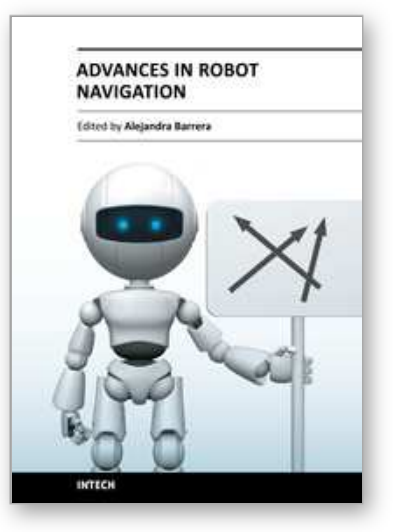

\author{
Advances in Robot Navigation \\ Edited by Prof. Alejandra Barrera
}

ISBN 978-953-307-346-0

Hard cover, 238 pages

Publisher InTech

Published online 15, June, 2011

Published in print edition June, 2011

Robot navigation includes different interrelated activities such as perception - obtaining and interpreting sensory information; exploration - the strategy that guides the robot to select the next direction to go; mapping - the construction of a spatial representation by using the sensory information perceived; localization - the strategy to estimate the robot position within the spatial map; path planning - the strategy to find a path towards a goal location being optimal or not; and path execution, where motor actions are determined and adapted to environmental changes. This book integrates results from the research work of authors all over the world, addressing the abovementioned activities and analyzing the critical implications of dealing with dynamic environments. Different solutions providing adaptive navigation are taken from nature inspiration, and diverse applications are described in the context of an important field of study: social robotics.

\title{
How to reference
}

In order to correctly reference this scholarly work, feel free to copy and paste the following:

Natasa Koceska, Saso Koceski, Pierluigi Beomonte Zobel and Francesco Durante (2011). Gait Training using Pneumatically Actuated Robot System, Advances in Robot Navigation, Prof. Alejandra Barrera (Ed.), ISBN: 978-953-307-346-0, InTech, Available from: http://www.intechopen.com/books/advances-in-robotnavigation/gait-training-using-pneumatically-actuated-robot-system

\section{INTECH}

open science | open minds

\author{
InTech Europe \\ University Campus STeP Ri \\ Slavka Krautzeka 83/A \\ 51000 Rijeka, Croatia \\ Phone: +385 (51) 770447 \\ Fax: +385 (51) 686166 \\ www.intechopen.com
}

\author{
InTech China \\ Unit 405, Office Block, Hotel Equatorial Shanghai \\ No.65, Yan An Road (West), Shanghai, 200040, China \\ 中国上海市延安西路65号上海国际贵都大饭店办公楼405单元 \\ Phone: +86-21-62489820 \\ Fax: +86-21-62489821
}


(C) 2011 The Author(s). Licensee IntechOpen. This chapter is distributed under the terms of the Creative Commons Attribution-NonCommercialShareAlike-3.0 License, which permits use, distribution and reproduction for non-commercial purposes, provided the original is properly cited and derivative works building on this content are distributed under the same license. 